\title{
LONG TERM MORPHOLOGICAL MODELLING
}

\author{
Sten Esbjørn Kristensen ${ }^{1}$, Rolf Deigaard², Martin Taaning ${ }^{2}$, Jørgen Fredsøe ${ }^{1}$, \\ Nils Drønen ${ }^{2}$ and Jacob Hjelmager Jensen ${ }^{2}$
}

\begin{abstract}
A morphological modelling concept for long term nearshore morphology is proposed and examples of its application are presented and discussed. The model concept combines parameterised representations of the cross-shore morphology, with a 2DH area model for waves, currents and sediment transport in the surf zone. Two parameterization schemes are tested for two different morphological phenomena: 1) Shoreline changes due to the presence of coastal structures and 2) alongshore migration of a nearshore nourishment and a bar by-passing a harbour. In the case of the shoreline evolution calculations, a concept often used in one-line modelling of cross-shore shifting of an otherwise constant shape cross-shore profile is applied for the case of a groyne and a detached breakwater. In the case of alongshore bar/nourishment migration an alternative parameterization is adopted. All examples are presented, analysed and discussed with respect to the question of realistic representation, time scale and general applicability of the model concept.
\end{abstract}

Keywords: Coastline model, Morphology, Groyne, Breakwater, Nourishment, Bar migration

\section{INTRODUCTION}

Shoreline morphology is the result of nearshore waves and currents acting on the coastline. Due to breaking of the waves and the currents generated close to the shore, longshore sediment transport is generated, and redistribution of the beach material will occur along the shoreline - from updrift areas, where the beach is eroded and the shoreline retreats, to downdrift areas, where the eroded beach material is accreted. Erosion corresponds to increasing longshore transport, whereas accretion corresponds to decreasing longshore transport, i.e. the shoreline evolution is connected to gradients in the longshore transport rates. In order to assess the long term evolution of the shoreline models for these phenomena must be formulated.

In order to formulate useful shoreline evolution models several issues have to be dealt with. Firstly a quantitative model for describing the longshore transport is needed. This includes the issue of incorporating the main physical mechanisms most important for the longshore transport and the alongshore gradient in the transport. Secondly a way of coupling the sediment transport and the changing shoreline morphology must be formulated. Thirdly the issue of computational time should be dealt with - i.e. the model should be able to produce plausible results within a reasonable (CPU) time horizon.

Furthermore, it is important to assess the situation to be modelled, in order to make sure that the model resolves the physics governing the specific case (different important examples could be: Long term predictions of the effect of coastal structures, assessment of effects of changes in wave climate or the effect of beach nourishments on the coast).

The problem of formulating a plausible shoreline evolution model can be approached in different ways. In the following a short summary of the most common model types for calculating shoreline response is given, to give the relevant background for describing the shoreline model concept which is the subject of the present paper.

\section{Simple one-line models}

The one-line model assumes that the shape of the coastal profile is maintained, and that continuity is obtained by shifting the entire cross-shore profile - shift in the onshore direction corresponds to erosion and shift in the offshore direction corresponds to accretion. This parameterization of the morphology yields the following version of the sediment continuity equation:

$$
\frac{\partial y_{\text {shore }}}{\partial t}=\frac{-1}{1-n} \frac{1}{h_{\text {act }}} \frac{\partial Q}{\partial x}
$$

\footnotetext{
${ }^{1}$ Department of Mechanical Engineering, Technical University of Denmark, Nils Koppels Allé Building 403, DK-2800 Kgs. Lyngby, Denmark. Corresponding author: sekr@mek.dtu.dk

${ }^{2}$ DHI, Department of Coastal and Estuarine Dynamics, Agern Allé 5, DK-2970 Hørsholm, Denmark
} 
where $y_{\text {shore }}$ is the shoreline position relative to some predefined alongshore axis, $n$ is the porosity, $Q$ is the solid volume sediment transport in the alongshore direction and $h_{a c t}$ is the active height of the profile. This simple relation was first proposed by Pelnard-Considère (1956).

The sediment transport models typically implemented in one-line models determine the longshore transport rate at a given point on the shoreline adopting the local wave climate and the local shoreline orientation, and does therefore typically not incorporate memory effects from updrift locations.

Some transport formulations used for one-line modelling are empirical formulas (e.g. the CERC formula) while other are more complex models based on sub-models of the physical processes, Deigaard et al. (1986). In the latter case the sediment transport is calculated on the basis of an actual coastal profile, which - combined with the assumption of alongshore uniformity in all flow quantities - transform waves from offshore to the shoreline (refraction, shoaling and breaking), calculate a longshore current driven by gradients in radiation stresses and model the concentration of suspended sediment in combined waves and current, to finally obtain the cross-shore distribution of longshore sediment transport. Integration across the profile of the longshore transport then gives a longshore transport rate that can be used as input to the shoreline model.

Common for all of the longshore sediment transport models (being it empirical or process based ones) typically used in one-line modelling, is that effects of local non-uniform wave fields (e.g. caused by coastal structures or offs-shore reefs), current inertia and refraction, streamline contraction and flow recirculation are not inherent in the models. These effects must be included through explicit schemes either as simple reduction factors on the transport or by modifying the wave climate locally due to refraction and/or diffraction (Hanson 1989, Alkyon Hydraulic Consultancy \& Research 2003).

\section{$\mathrm{N}$-line models}

An interesting extension of the shoreline model is the n-line model or multi-layer model, in which the coastal profile is schematised by a series of lines/layers. The layers are mutually coupled through a crossshore transport formulation, which will force them towards an equilibrium configuration. The longshore transport is determined for each point along the shoreline and for each layer based on the angle between the incident waves and the local orientation of the shoreline normal. The $n$-line model concept has been developed in order to handle cross-shore transport in the simplified shoreline models, and examples of this are the model of Bakker (1969) and the PonTos-model by Steetzel \& Wang.

\section{D area models}

A second class of morphological models is the 2DH/Q3D area models. In these model types the determination of wave and flow fields are typically based on phase averaged formulations, which allow larger time step increments compared to phase resolved models.

The 2DH area models typically calculate the transformation of wave energy, wave angle and wave period from an off-shore boundary to the shoreline (wave refraction, shoaling, diffraction and breaking), and use this information to drive a flow model - both over a given bathymetry - to give the depth averaged current field in two horizontal dimensions. Based on the areal distribution of wave characteristics and current field, the areal distribution of the sediment transport field is evaluated. The divergence of the sediment transport field over each computational cell yields the rate of change of the local bed level, which is used to update the morphology for the next time step.

Different approaches to calculate the sediment transport in these model types are reported in the literature, ranging from empirical formulas (see e.g. Soulsby 1997, Roelvink et al. 2006) to sophisticated intra-wave, quasi-3D models for the local hydrodynamics (undertow, streaming, wave-current boundary layers, wave generated turbulence, etc.) and sediment suspension, to get the total sediment transport (see e.g. Fredsøe and Deigaard 1992).

Common to these model types is that they are not - as is the case in the one-line model - bound to the assumption of alongshore uniformity, but include effects of non-uniformity in the bathymetry and they may also incorporate the presence of coastal structures sheltering/reflecting the waves and block the currents.

In principle such a model type would yield a very good basis for simulations of the detailed morphological evolution around say a breakwater, and has proven in many cases to give good results over a shorter time scale (e.g. Brøker et al. 2007, Drønen and Deigaard 2007). There are however some inherent issues that have to be solved before the model type will be feasible for long term simulations. First, the 
CPU time is still a limiting factor when running such a model for many years and decades. Furthermore, the cross-shore profile may degenerate when run over a long period of time, and will in all cases need a large degree of calibration to produce reasonable results. Also discussions on the numerical diffusion, numerical instability (Johnson \& Zyserman 2002, Callaghan et al. 2006) and numerical stiffness add some question marks to the applicability of this model type for long term morphological runs.

\section{INTRODUCTION OF THE MODEL CONCEPT}

In the present paper a model concept is formulated as a hybrid of the detailed $2 \mathrm{DH}$ area model (for waves, currents and sediment transport) and a geometric simplification and hence parameterization of the morphology (the one-line model is an example of this).

The main idea is to use a 2DH area model to represent the hydrodynamics and the sediment transport over a generally non-uniform bathymetry including effects of blockage of waves/current by coastal structures - and to couple this information with a morphological updating scheme based on a simplified parameterization of the morphology.

The one-line model concept is one example of a parameterized morphological scheme used for shoreline evolution, but the basic idea can be used to construct other morphological parameterizations either when approaching different morphological phenomena or if sophistications of the one-line parameterization are sought. Generally, the main challenge for the modeller in the present model context is to choose a parameterization of the morphology that resembles the real morphology the best.

In order to connect the two modelling approaches, the morphological evolution is determined on the basis of the cross-shore integrated longshore sediment transport, and the update of the morphology from one time step to the next is carried out by updating a single or few morphological parameters which characterise the coastal profile rather than the bed level in individual mesh elements.

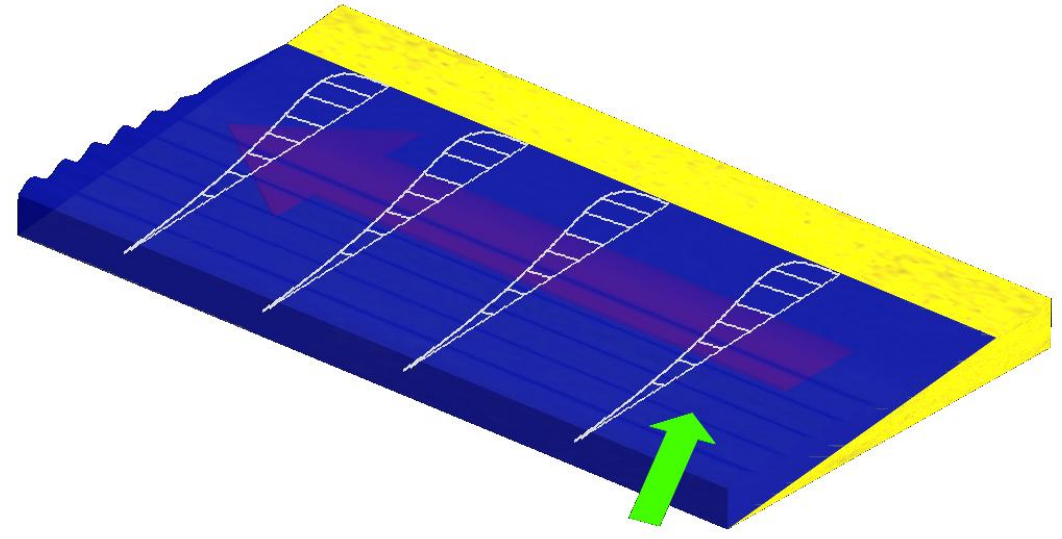

Figure 1. The 2DH sediment transport field determined by a 2DH model is converted into a 1D longshore drift by integration of the transport along coastal profiles.

The same ideas were in principle used by Hansen et al. 2005 to study three-dimensional bar morphology, and the present study can be seen as a continuation of investigating the principles used in that study.

In the present paper two different morphological parameterization schemes for two different situations have been tested. Shoreline response is calculated using a scheme similar to the one-line model. Alongshore migration of bars and nourishments are calculated using an alternative scheme, where the morphology is parameterized differently to resolve that specific situation.

Given the simplifications introduced by the parameterization of the morphology, the model concept has several advantages seen in the context of long term modelling: 1) The 2DH models give a more realistic description of the horizontal spatial effects on the flow and sediment transport compared to the simple oneline models, 2) long term degeneration in the cross-shore profile is avoided and 3) CPU time is significantly lower compared to a full 2DH/Q3D morphological model. 


\section{Implementation of the model concept}

The model concept is in principle not bound to any specific coastal model system. The numerical implementation presented here is based on a combination of scripts and functions interacting with the coastal model system MIKE21 FM from DHI. The coupled model system of DHI consists of a spectral wave module MIKE21 SW, which solves a transport equation for the wave action density, a 2DH depth integrated flow model MIKE21 HD/FM that solves the non-linear shallow water equations and a sediment transport module MIKE21 STP, which calculates the sediment transport based on the values of local hydrodynamic quantities.

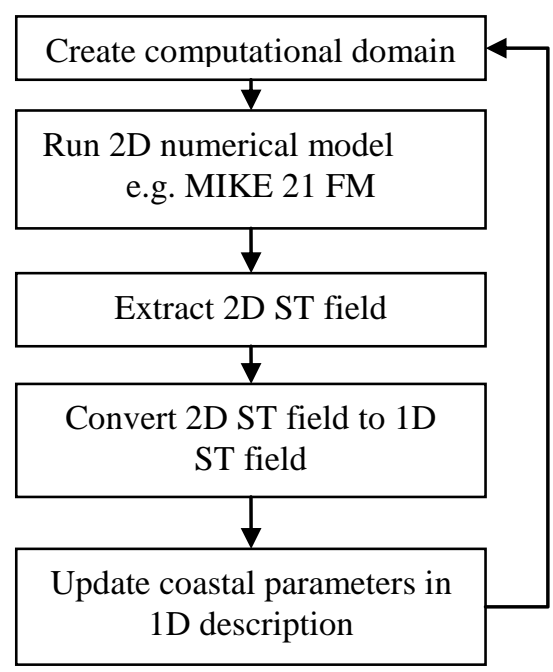

Figure 2. Flowchart of the morphological model

The model system is used to determine the $2 \mathrm{DH}$ sediment transport field, and the morphological feedback is performed by cross-shore integration of the longshore transport, updating the coastal parameters and writing the updated bathymetry to a new mesh file. The morphological loop is closed by calling the model system once again.

\section{APPLICATION OF THE MODEL- SHORELINE EVOLUTION}

The model concept is applied to the case of shoreline evolution around coastal structures. Two cases are considered where an idealized coastline is interrupted by a coastal structure: In the first example a groyne field is considered and in the second example the case of an offshore breakwater is considered.

\section{Coastline evolution around a groyne field}

A groyne field is used in the first example. It is assumed that the form of the coastal profile is maintained throughout the domain. The morphological feedback is thus introduced by shifting the shoreline in the on-/offshore direction depending on whether there is erosion or deposition, as indicated in Figure 3. The rate of on-/offshore migration of the shoreline is determined from the $1 \mathrm{D}$ continuity equation given in eqn. 1.

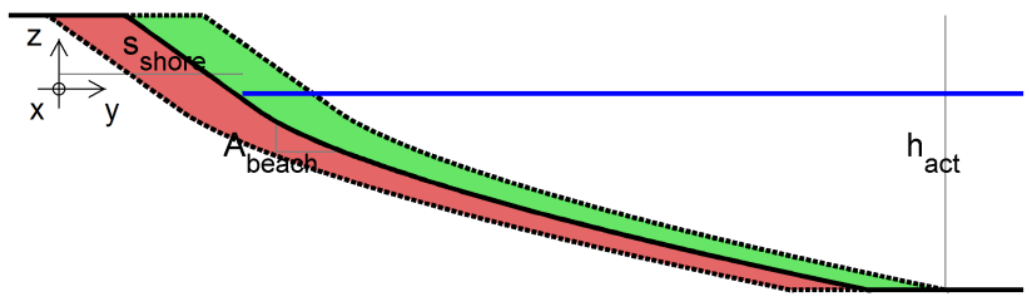

Figure 3.The form of the coastal profile may be maintained, while satisfying sediment continuity by shifting the profile in the on-/offshore direction. 
The result of applying the morphological model to a groyne field, where an infinite number of groynes are represented by periodic boundary conditions on the lateral boundaries, is shown in Figure 4. A wave climate consisting of 2 waves approaching the shoreline from $+15 \mathrm{deg}$ and $+25 \mathrm{deg}$ from the initial shore normal is used (a positive angle means that the wave direction is rotated anticlockwise compared to a shore-normal approach). The significant wave height is in both wave conditions $1.5 \mathrm{~m}$ at the offshore boundary, and the peak wave period is $7 \mathrm{~s}$. The groyne is long compared to the surf zone width. The 2DH transport field is indicated in the two bottom panels as black vectors, while the longshore variation of the integrated longshore drift is shown in the top panels. Both figures show that the groyne decreases the transport locally - becoming zero at the groyne location - and that the transport recovers downdrift the groyne.

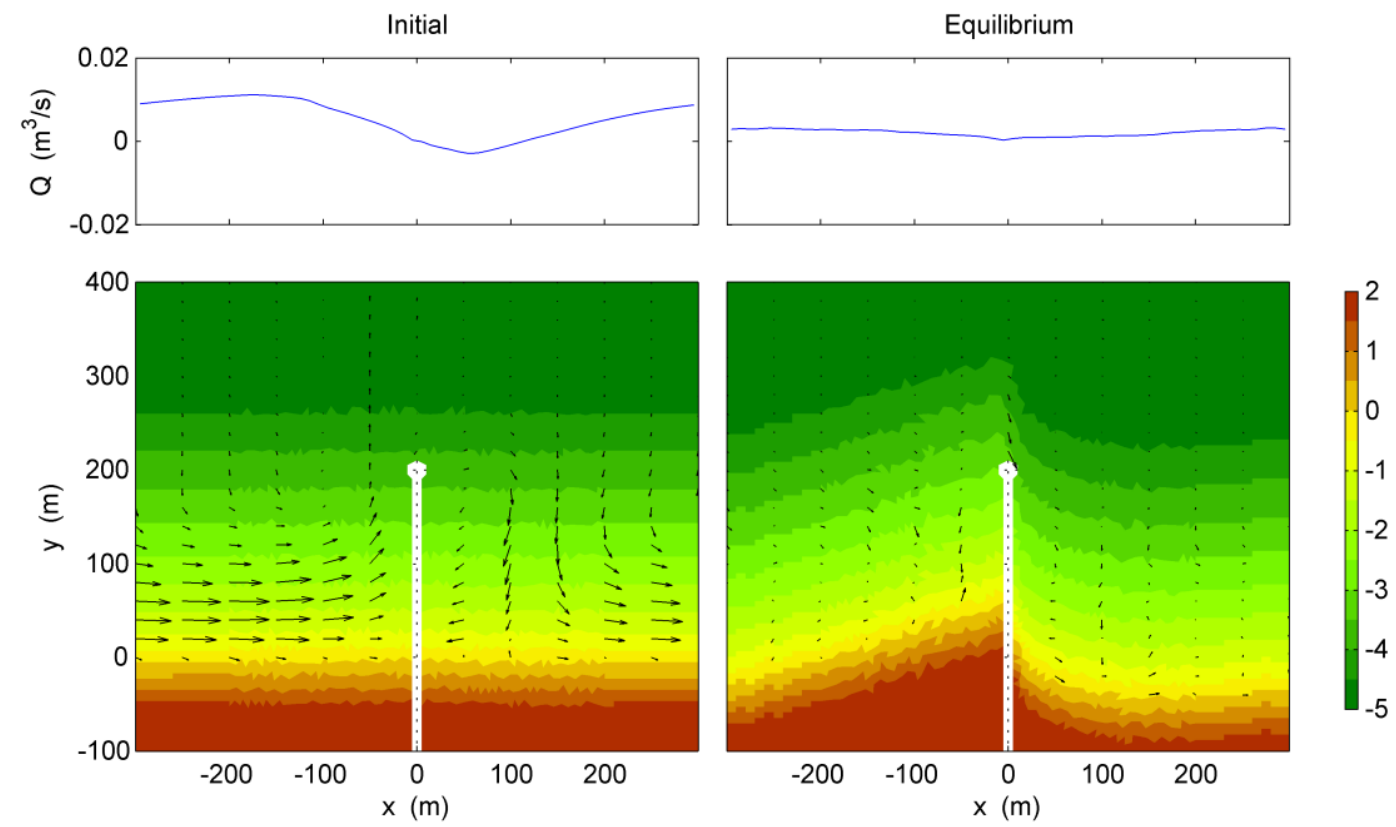

Figure 4. Morphological evolution around a groyne in a groyne field (periodic BC on West and East boundaries). Left panel: Initial bathymetry, Right panel: Equilibrium bathymetry. Colours indicate the bed level in metres. The top panels show the instantaneous long shore transport.

The morphological evolution of the shoreline in the groyne field seems reasonable, because it features upstream accretion and downstream erosion as would be expected for this problem. The equilibrium conditions are according to Figure 5 obtained after approximately 4 months. The fact that the model is capable of determining an equilibrium solution for a given forcing is interesting because the method may be used to quantify the effect of the groyne field on the shoreline for different groyne configurations in different wave climates.

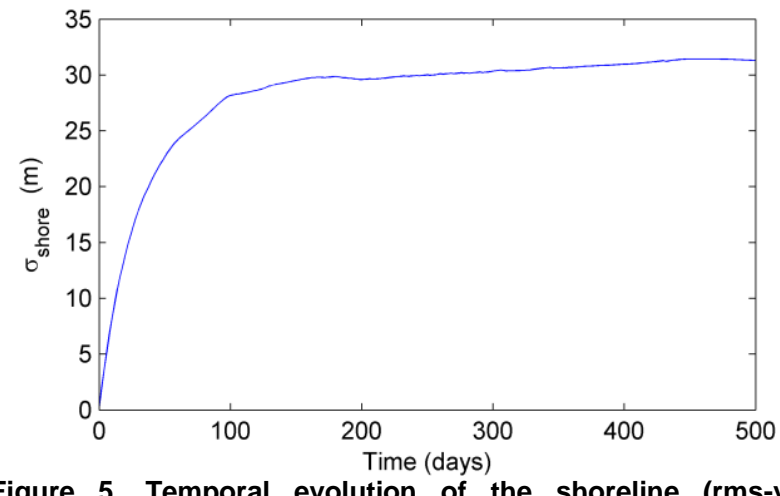

Figure 5. Temporal evolution of the shoreline (rms-value). Equilibrium conditions are obtained after approximately 4 months. 
It should be noted that - as is the case in all one-line modelling - the form of the cross-shore profile is maintained throughout the domain and simulated time, and the model will quantify the morphological change only within the restrictions imposed by the modeller. Possible further development could involve changes to the coastal profile, such as steepening on the upstream side and flattening on the downstream side or development of local erosion at the groyne head.

\section{Coastline evolution behind a breakwater}

The next example illustrates the shoreline evolution behind a detached coastal breakwater. The breakwater is constructed on an idealized uniform coastline and subject to a varying wave climate consisting of three waves with the wave directions $+10 \mathrm{deg},+5 \mathrm{deg}$ and $-5 \mathrm{deg}$. The significant wave height is $1 \mathrm{~m}$, and the peak wave period is $7 \mathrm{~s}$. The breakwater is positioned in the middle of the active part of the coastal profile, which means that using the same method for updating the shoreline as was done in the case of the groyne, will effectively result in the profile penetrating the structure as the profile moves off-shore, i.e. introducing a flux of sediment through the structure. The sediment flux through the structure is avoided by preventing the model from changing the bathymetry on the farshore side of the structure in profiles where the breakwater is present see Figure 6.

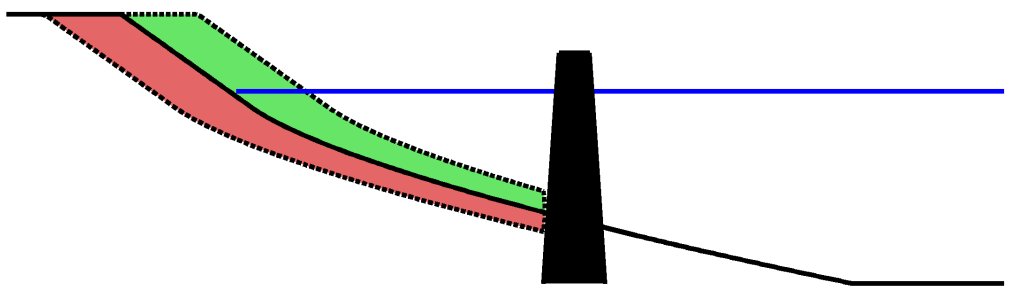

Figure 6. Sketch of a coastal profile where all morphological change is inhibited on the farshore side of a coastal breakwater. The active height of the coastal profile decreases when the shoreline advances. Continuity is therefore obtained through numerical solution.
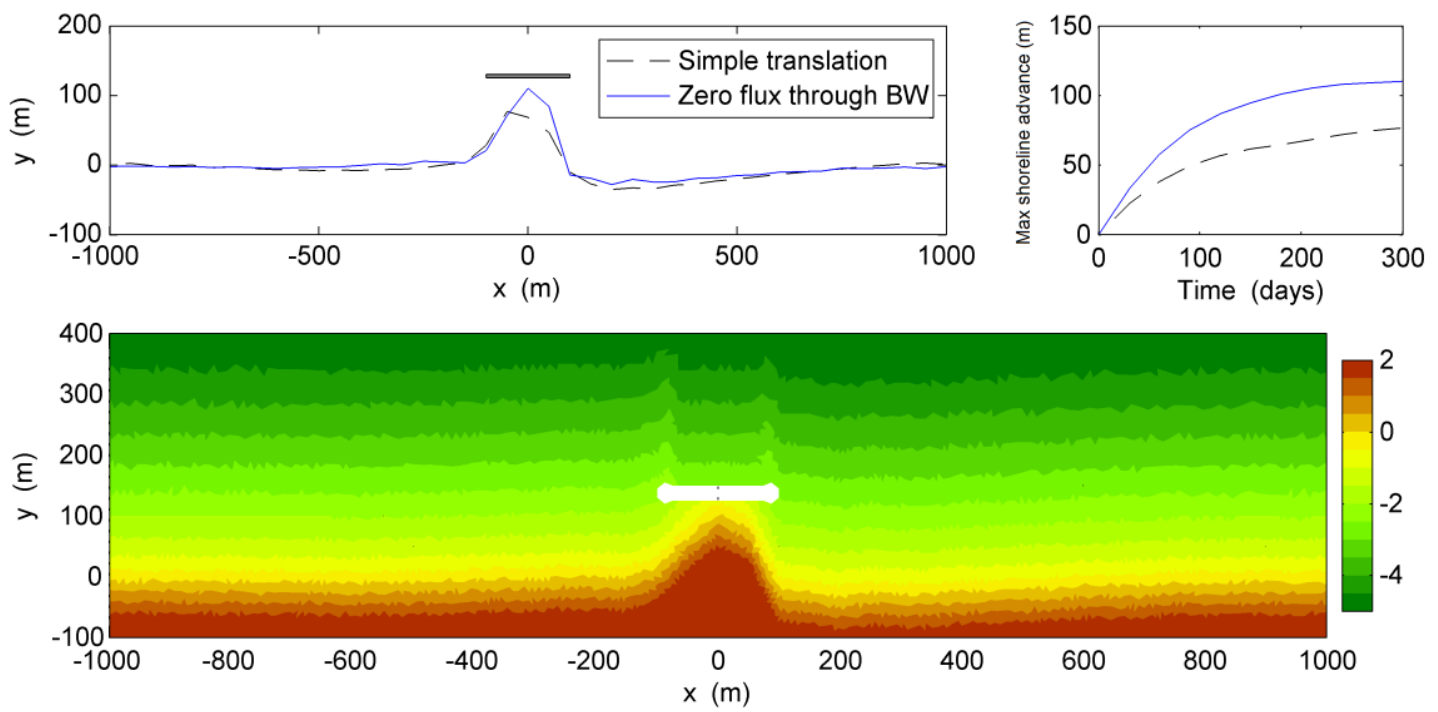

Figure 7. Shoreline evolution behind a breakwater subject to waves from three different directions. The net transport is to the right. A zero sediment flux is imposed through the break water. Colours indicate bathymetry in metres.

The result of using this simple method is shown in Figure 7. The bottom panel shows the 2D bathymetry after equilibrium has been reached. The result shows a formation of a tombolo planform behind the breakwater. The planform is asymmetric due to the asymmetric forcing from the waves, and downstream erosion is predicted, up to a distance of $300 \mathrm{~m}$ from the structure. The top panels compare this solution with a solution obtained where the sediment flux through the structure is allowed. The comparison shows that that model predicts a decrease in timescale of the morphological development due to the 
reduction in active height of the coastal profile - which is expected. Furthermore, the maximum accretion of the shoreline behind the breakwater increases because the bed level on the farshore side of the breakwater is maintained.

The example shown in Figure 7 represents a case where an increase in cross-shore complexity of the morphological evolution improves the result significantly. Promising tests have also been performed with an additional increase in model complexity, where it was made possible for sediment to bypass in front of the structure. The profile offshore of the structure could also evolve, and if the depth was small enough sediment transport would happen offshore of the breakwater.

\section{SIMULATIONS WITH PROFILE EVOLUTION}

In order to apply the model concept to a wider range of problems, a simple extension is proposed, where the longshore transport is integrated over part of the coastal profile. The morphological evolution is similarly restricted to this local part of the profile. The extension is visualized in Figure 8, where the amplitude of a bar is updated.
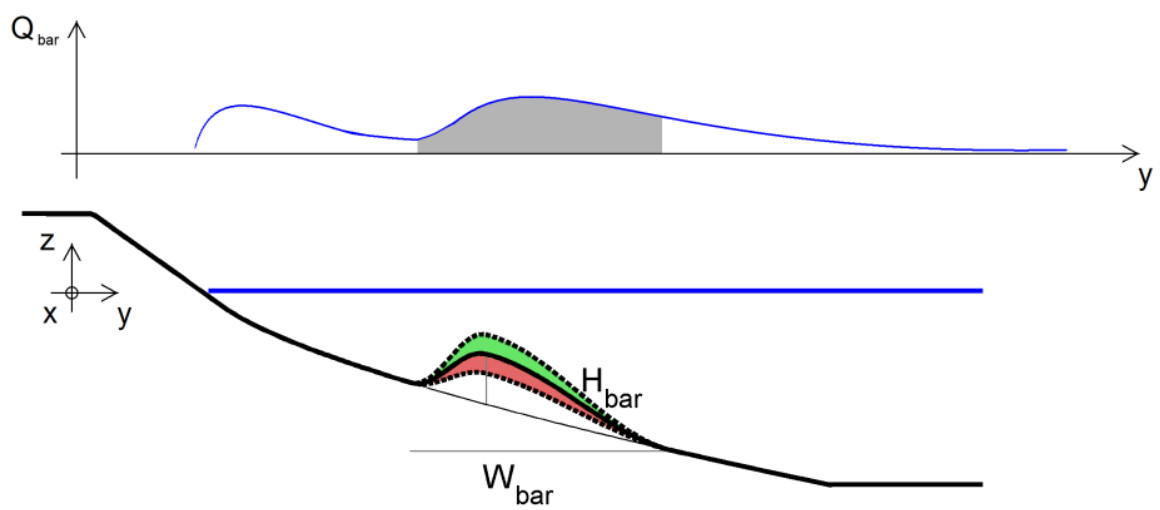

Figure 8. The model concept is used to update local features on the coastal profile. This allows the model to be used on a broader range of problems.

\section{Morphological evolution of a shoreline nourishment}

The model is applied to a case where beach nourishment is performed on an otherwise straight coast. The cross-shore extent of the nourishment is assumed to be limited to the area around the shoreline, as indicated in Figure 9. Furthermore it is assumed that the nourishment consists of sand which is similar to the existing sand, and that the nourished sediment is only redistributed in the longshore direction.

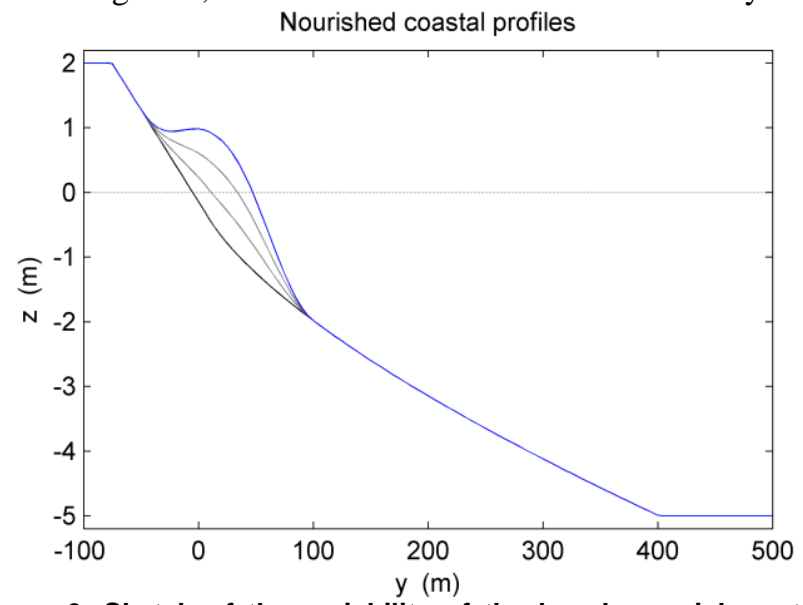

Figure 9. Sketch of the variability of the beach nourishment. The blue line indicates the initial profile in the nourishment area.

The nourishment is subject to a constant wave climate with a significant wave height of $1.5 \mathrm{~m}$, a peak wave period of $7 \mathrm{~s}$, and waves approaching the shoreline from $+10 \mathrm{deg}$. In a classic one-line model the 
solution to this type of problem is a diffusive redistribution of the salient formed by the nourishment. This is because the 1D model will predict the transport to be only a function of the coastline orientation and predict the same transport rate on a non-nourished profile as it would on a profile on a central section of the nourishment. Figure 10 shows the model prediction. Immediately after construction, the model predicts a rapid diffusive redistribution of the nourishment at the two ends of the nourished area in the same manner as would be expected from a classic 1D model. With time the variation in the longshore transport becomes distributed over the entire length of the nourishment, and the whole nourishment migrates in the downdrift direction while it is still being smoothed out. The movement of the centroid of the nourishment shows a constant migration rate of $0.9 \mathrm{~m} /$ day for this configuration.

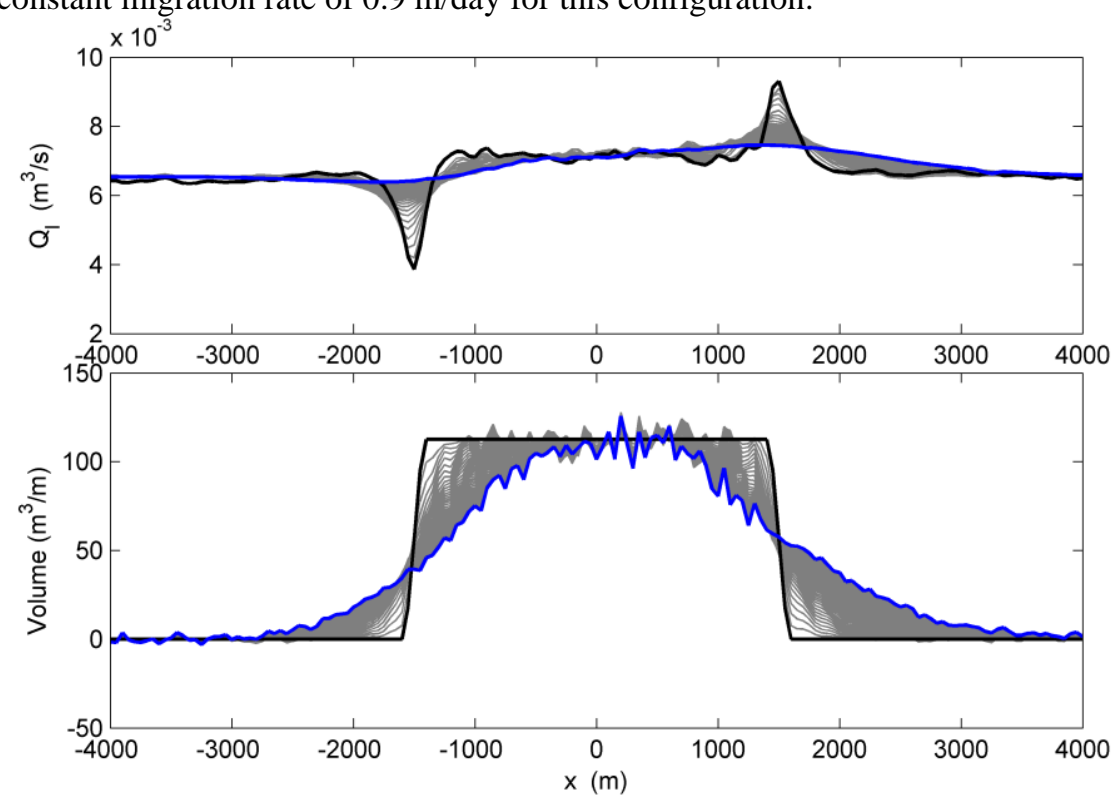

Figure 10. Time stack of the simulated longshore transport and the nourishment volume. Black curve: Initial condition, Blue curve: Final condition.

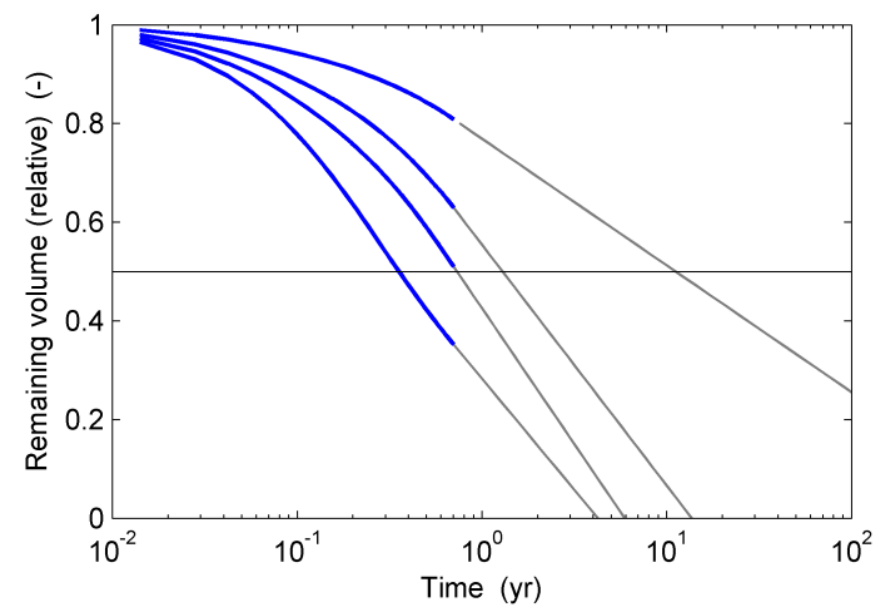

Figure 11. Comparison of the physical performance of different nourishments. Only the length of the nourishment project is varied. The lengths shown in the figure are: $L=800 \mathrm{~m}, L=1200 \mathrm{~m}, \mathrm{~L}=1600 \mathrm{~m}$ and $\mathrm{L}=3000 \mathrm{~m}$. Blue curves: simulations, grey lines: extrapolations.

It is important to describe the life time of a nourishment. This may be done in terms of the remaining relative volume of nourished sediment within the original nourishment area. Dean et al. (1992) show that the life time of a nourishment is dependent on the length of the nourishment. A long nourishment will have a substantially longer life time than a shorter but otherwise similar nourishment. Figure 11 shows a 
comparison between different nourishments. The only difference between the nourishments is the length. The volume of the nourishment per unit length is constant, and the total volume is therefore proportional to the length. The model clearly predicts an increase in life time for the nourishment as the length is increased - which is expected.

\section{Alongshore migration of a bar}

The model concept may be applied to a more complex problem like the alongshore migration of a bar. In the case considered an alongshore uniform bar is present at the upstream end of the domain. The bar extends into part of the domain and there will be large gradients in the longshore transport along the bar, which will grow into the domain. Constant wave conditions are given at the offshore boundary with significant wave height of $2 \mathrm{~m}$, a peak wave period of $6 \mathrm{~s}$ and the angle between the approaching waves and the shoreline normal is $+49 \mathrm{deg}$.

Due to the steady supply of sediment into the domain from updrift the bar will grow in the downdrift direction. The model addresses the questions of the migration rate and the shape of the growing bar. The sediment transport near the tip of the bar is described from the pattern of the depth integrated wave-driven currents. As a first approach the cross-shore location of the bar inside the domain is therefore determined from the flow field, which in turn to a large degree is determined by the location of the bar at the upstream boundary of the model domain. The cross-shore migration of the bar is therefore determined by the streamlines extending from each side of the bar on the upstream boundary as indicated in Figure 12.

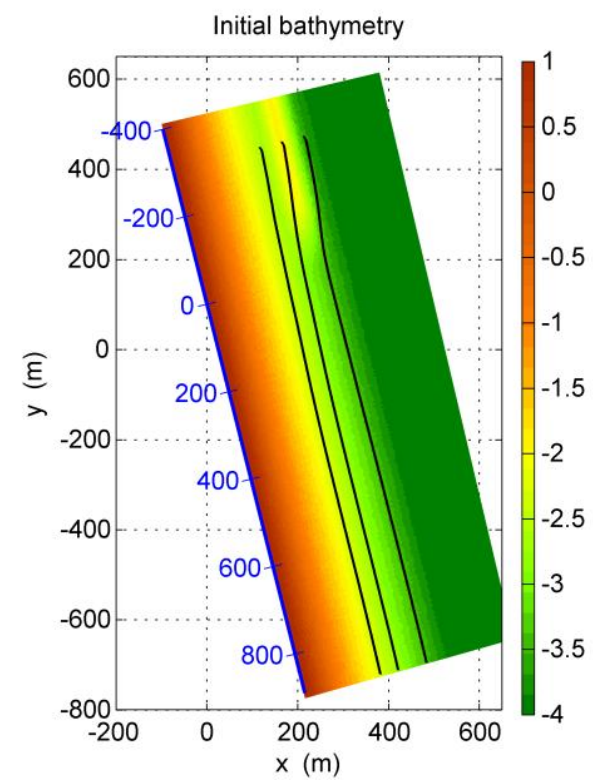

Figure 12. 2D plot of the initial bathymetry with an alongshore migrating bar. Colours show bed level in metres, and the three black curves indicate streamlines which define cross-shore forcing of the bar.

The cross-shore position of the bar follows a simple response function which resembles that was used by Plant et al. (1999) and Hansen et al. (2005).

$$
\frac{\partial s_{\text {bar }}}{\partial t}=\frac{1}{T_{\text {scale }}}\left(s_{\text {stream }}-s_{\text {bar }}\right)
$$

where $s_{\text {bar }}$ represents the cross-shore location of the bar, $s_{\text {stream }}$ is the cross-shore location of the streamline and $T_{\text {scale }}$ is a timescale which remains to be specified. Plant et al. (1999) suggests that $1 / T_{\text {scale }}$ should be a growing function of the incident wave height, because larger wave heights will lead to a larger intensity of the cross-shore transport. The intensity of the longshore transport may also be used as proxy for the time scale of cross-shore movement. In this simple example where the wave climate is constant the time scale for the cross-shore movement is taken to be a function of the bar volume only. $T_{\text {scale }}$ is therefore selected such that it spans the range from zero (in practice one time step in the morphological model) to a user 
specified maximum value $T^{*}$ scale. In this simulation a value of 15 hours has been used for $T^{*}{ }_{\text {scale. }}$ The bar will thus react instantly to the streamlines for profiles where the bar height is zero, and it will react according to $T^{*}$ scale for profiles with a volume corresponding to the updrift bar.

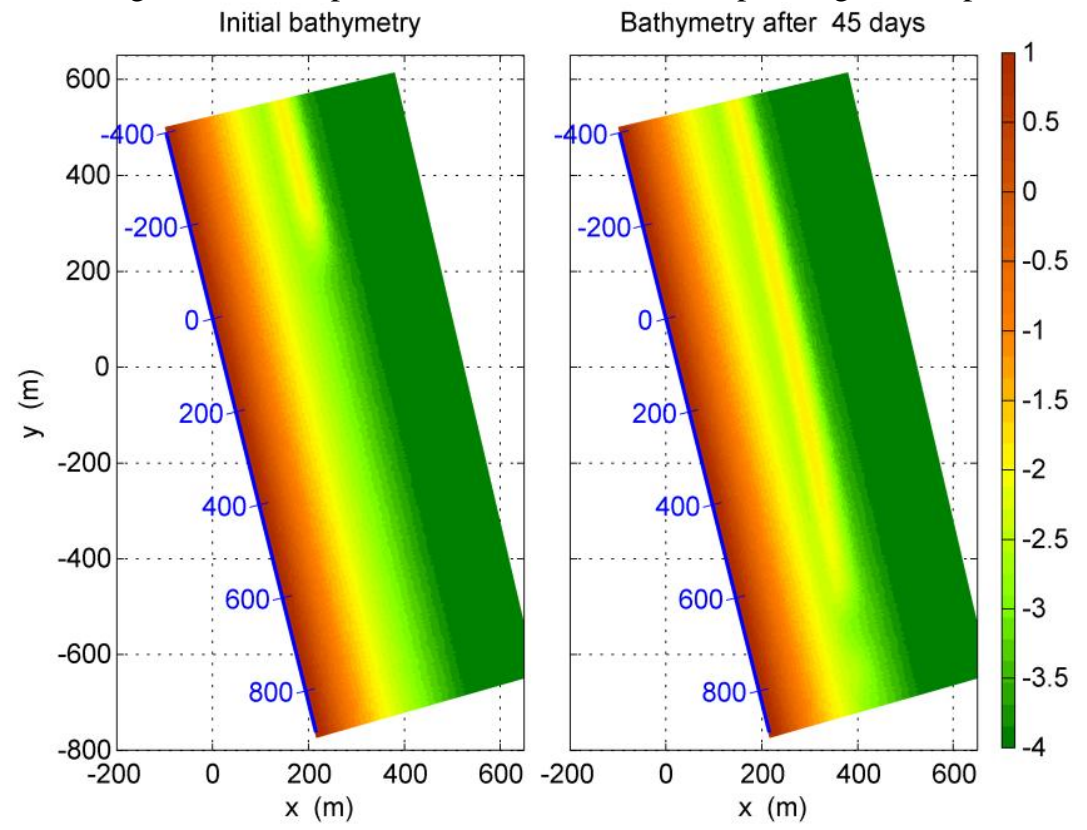

Figure 13. Comparison between the initial bathymetry and the bathymetry after 45 days of simulated time. Colours indicate bed level in metres. The blue scale defines an r-axis which runs parallel to the shoreline.

The simulation result is illustrated in Figure 13. The left panel shows the initial bathymetry while the right panel shows the bathymetry after 45 days. The figure shows that the model predicts an alongshore migration of the bar, and that the bed level along the bar crest is maintained (see Figure 14). The crosssectional form of the bar is maintained because it is prescribed in the same manner as it was for the nourishment shown in Figure 9. This increases effectively the stability of the model and makes it more robust and applicable for long term simulation. The alongshore migration of the bar is approximately 16 $\mathrm{m} / \mathrm{day}$.

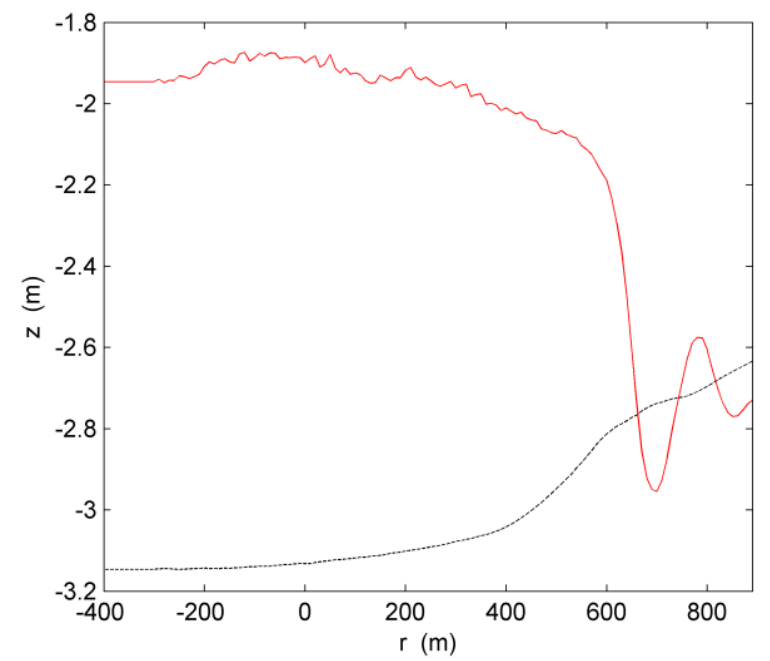

Figure 14. Longshore configuration of the bed level after 45 days of simulation. The bed levels are shown along the bar crest (red curve) and the corresponding bed level for the original unbarred coastal profile (black curve). 
The smooth variation of the cross-shore position of the bar is a direct result of using streamlines to determine the cross-shore forcing. Over the head of the bar the streamlines are deflected towards the shore because the onshore forcing by radiation stresses cannot be balanced by the wave set-up alone. A circulation current is rather generated, which drives a net onshore current over the head of the bar. The morphological model forces the head of the bar to migrate rapidly onshore during the first couple of days, after which the distance from the shoreline to the head of the bar remains almost constant as shown in Figure 15 where the bar position is schematised at different time steps.

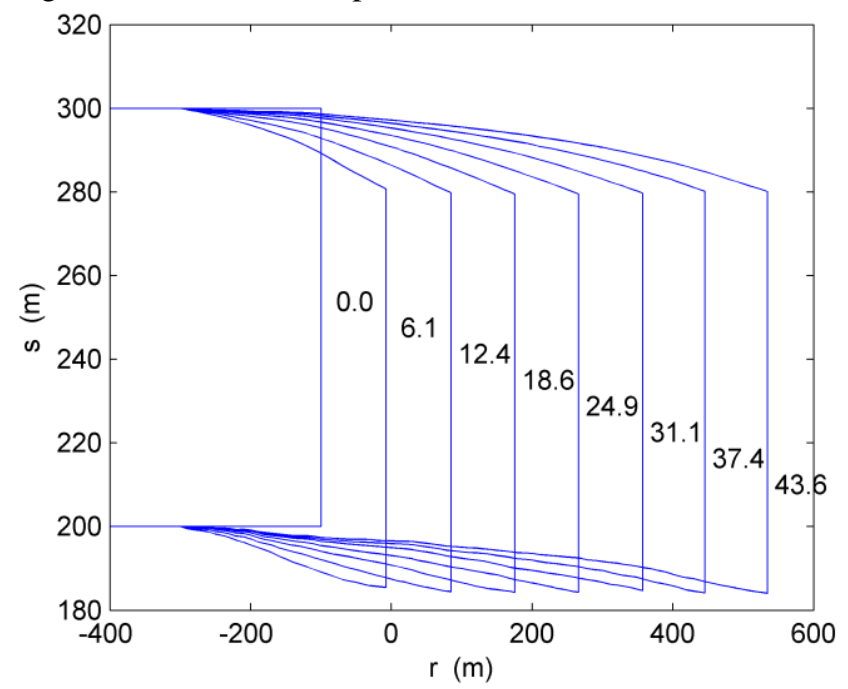

Figure 15. Schematic representation of the bar position at different time steps. The numbers in the plot indicate the number of days simulated. The r-axis is the longshore axis, and the s-axis is the cross-shore axis.

The lack in cross-shore forcing from undertow means that the trunk section of the bar does not return to the same cross-shore position as it is on the upstream boundary. The position of the bar can be maintained by introducing a forcing of the bar towards the "equilibrium cross-shore position" for the profiles away from the head of the bar resulting in the solution shown in Figure 16. The added forcing towards the equilibrium position is of the form:

$$
\frac{\partial s_{\text {bar }}}{\partial t}=\frac{1}{T_{\text {scale }}}\left(\xi \operatorname{mean}\left(s_{\text {eq }}, s_{\text {stream }}\right)+(1-\xi) s_{\text {stream }}-s_{\text {bar }}\right)
$$

$\xi$ represents an blending function which reduces the effect of the added forcing close to the head of the bar. $s_{e q}$ is the equilibrium position of the bar, which is determined by the cross-shore transport. The function $\xi$ is set to vary linearly between 0 and 1 in the first 200 m upstream of the bar front. 


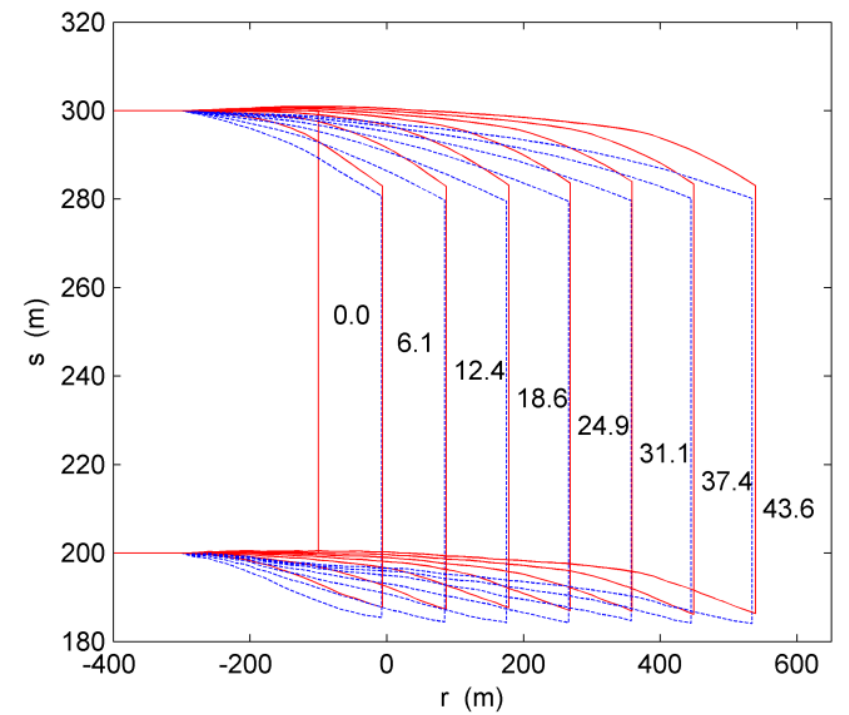

Figure 16. Schematic representation of the bar position at different time steps. The numbers in the plot indicate the number of days simulated. Blue dashed curve: Bar position when following streamlines (result from Figure 15). Red solid curve: Bar position with an added forcing towards the upstream cross-shore position.

The result of the added cross-shore forcing is that the bar now migrates into the domain with a constant planform as indicated in Figure 17. The result is obtained through a rule-based forcing based on the assumption that for the given wave conditions an equilibrium position exists for a longshore bar, and that it tends to return to this position.

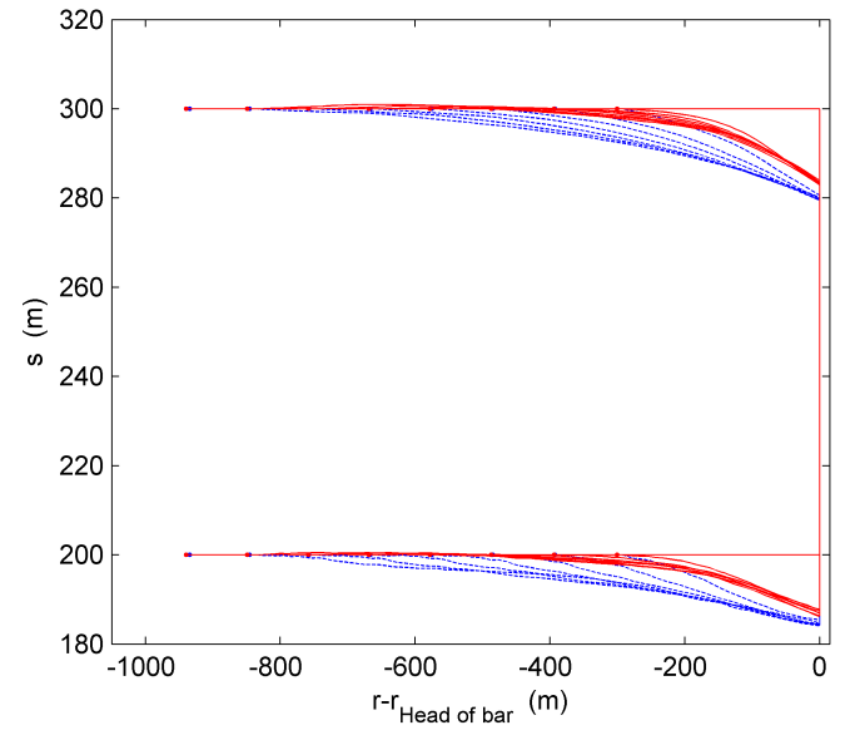

Figure 17. The form of the migrating bars. The effect of the added cross-shore forcing is that the bar now migrates into the domain with a fixed planform. The origin of the horizontal axis is at the instantaneous position of the bar front. Blue dashed curve: Bar position when following streamlines. Red solid curve: Bar position with an added forcing towards the upstream cross-shore position.

\section{Bypass of bar at a harbour}

A simulation of the morphological development of a bar that bypasses the harbour Hvide Sande at the Danish Noth Sea coast is performed in order to determine whether the streamline approach described previously gives reasonable results. This particular problem has been examined by Grunnet et al. (2009) in a study to investigate a revised harbour layout with improved conditions for bypass of sediment. In the original work of Grunnet et al (2009) the 2DH/Q3D model was validated against field measurements from 
several storm events. One of these events is selected, where a single bar bypassed Hvide Sande harbour during 5 days in 2003.

In this case the morphological evolution on a real coast with a complex bathymetry is simulated. The coast is not easily parameterised due to the marked variation in coastal profiles at the open coast and those at the harbour. The morphological development of particular interest for this problem is however the migration of the longshore bar. The coastal parameters being updated are the cross-shore position of the bar and the bar height. These parameters may be used to describe the evolution of the bar over the domain. The bar is therefore added onto a baseline bathymetry which essentially is the initial $2 \mathrm{D}$ bathymetry where the bar feature is removed in the active part of the domain, see Figure 18. The bar parameters are then reconstructed corresponding to the initial bathymetry before the storm. The reconstructed bathymetry is very close to the initial surveyed bathymetry, and contains the same volume of sediment in the bar.

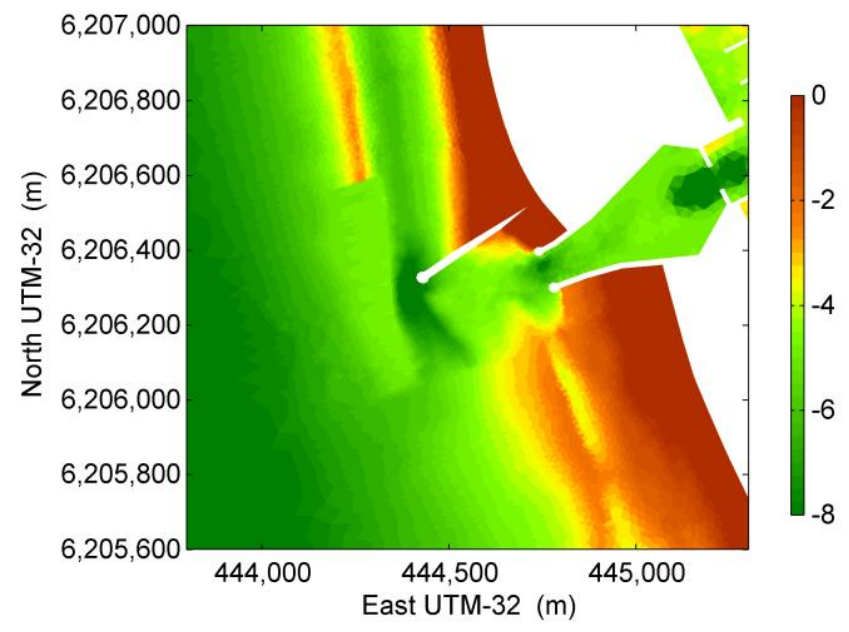

Figure 18. A baseline bathymetry is constructed where the bar features on the active part of the profile are removed. Colours indicate bed level in metres.

The motivation for using the baseline bathymetry is that the complexity of the coastal configuration is easily maintained, while the bar is allowed to migrate freely over the bathymetry. The simulation with the model describes only the dynamics of the bypass bar and does not reflect other changes in the coastal profile.

Figure 19 shows the surveyed conditions after the storm together with the result obtained from Grunnet et al. (2009) and that obtained with the present model concept. The head of the bar is initially located at the $100 \mathrm{~m}$ mark on the rs-coordinate system shown in the figure. During the 5 day storm with wave heights up to $4.5 \mathrm{~m}$ the bar migrated approximately $400 \mathrm{~m}$.

The features of the bar simulated by the present model resemble those seen in the survey (and in the more detailed morphological simulation), where the bar tends to turn towards the shoreline, and the crosssectional form of the bar seems to be maintained. There is a tendency for the hybrid model to move the bar too far onshore, possibly because the effect of cross-shore sediment transport processes has not been considered. The bathymetry is quite complex and almost continuous dredging is carried out. It is therefore not possible to prescribe an equilibrium location for the bypass bar and only the streamlines have been used to determine the evolution of the planform of the bar.

\section{DISCUSSION AND CONCLUSIONS}

A morphological modelling concept has been developed, which uses detailed two-dimensional area models to describe the wave-, current- and sediment transport fields. When making the morphological update the evolution of the coastal profile is restrained by allowing only a single or few degrees of freedom, such as the coastline position or the volume/position of a bar. The morphological evolution is therefore based on integrated sediment transport rates and rule-based descriptions of the profile evolution. The concept tries thus to bridge the gap between existing detailed two-dimensional morphological models and simple one-line models for the coastline evolution. The primary motivation of the concept is to (1) improve the calculated longshore transport compared to that determined by conventional $1 \mathrm{D}$ transport models and 
(2) allow simulations over longer time spans by restraining the distortion of the coastal profile which often occurs in two-dimensional models.
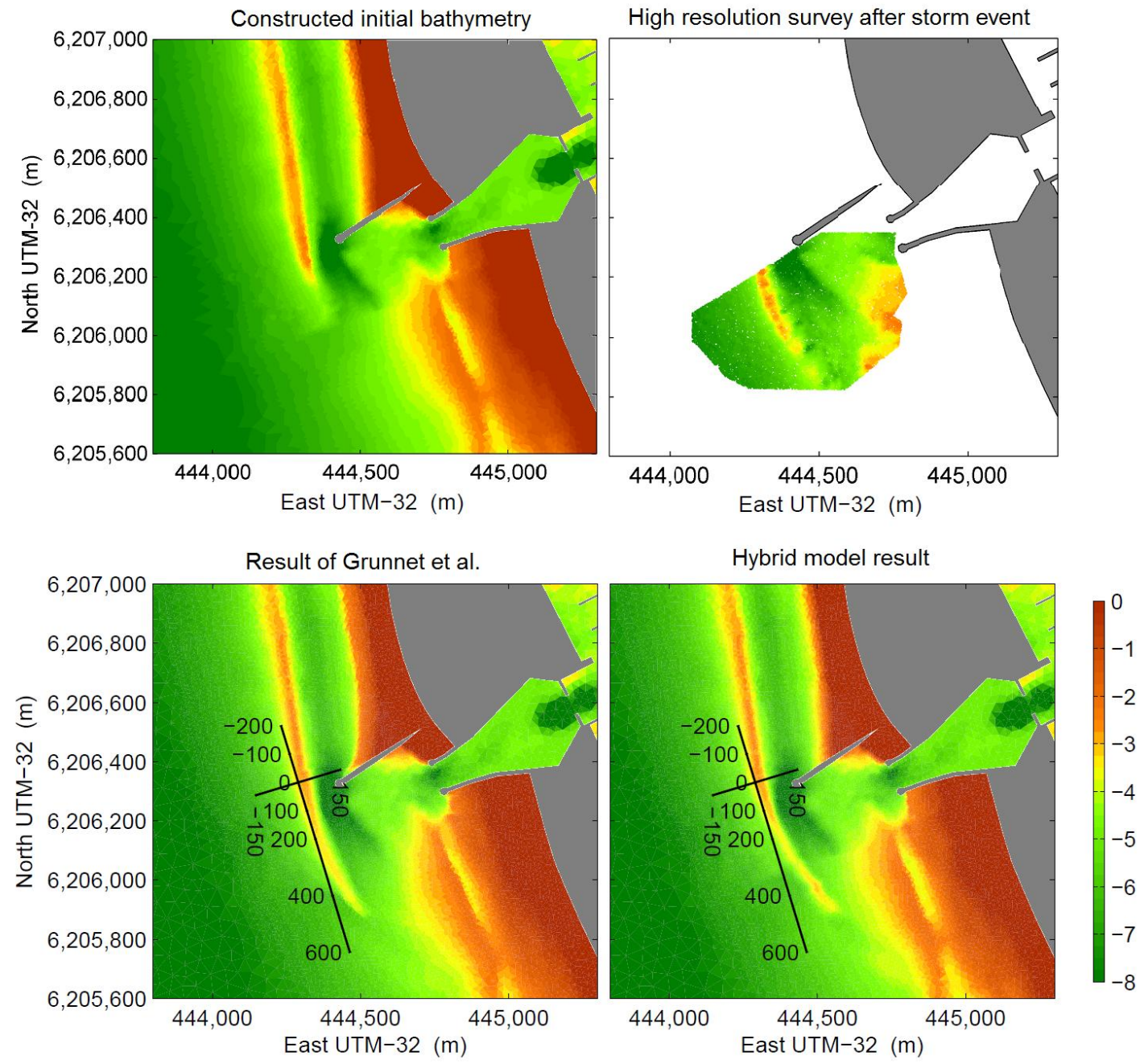

Figure 19. Comparison between surveyed and modelled post storm bar configuration. The pre storm bathymetry is also shown in the top left panel. All colours indicate bed level in metres.

In the calculation of the longshore transport the model includes more physical processes than one-line models for coastline evolution. In the littoral drift models used with one-line models the longshore transport depends only on the orientation of the coastline relative to the incoming waves. In the twodimensional models effects included are: e.g. inertia effects in the longshore current, horizontal circulation currents, effects of non-parallel bed contours on the wave field and the lee-side effect of structures on the longshore transport

In detailed morphological models the description of the cross-shore transport is still not accurate enough to make realistic simulations of the evolution of a coastal profile over long periods. Typically the bars in a profile will be smoothed out or they will be too peaked. The bars will also often tend to migrate in the offshore direction only. For longer term modelling it can therefore be worth to abandon the profile modelling and use a schematized profile in the simulations and still maintain a realistic shape of the profile during an extensive simulation period.

In addition the limitations put on the evolution of the coastal profile allows for much longer morphological time steps compared to the refined two-dimensional models. This will allow for longer 
simulations to be made in an ordinary engineering study and will make it possible to simulate a larger number of different cases.

\section{ACKNOWLEDGMENTS}

The first author has been supported by a grant from the Danish Agency for Science Technology and Innovation.

This work has been partly supported by the Danish Council for Strategic Research (DSF) under the project Danish Coasts and Climate Adaptation - flooding risk and coastal protection (COADAPT), project no. 09-066869.

\section{REFERENCES}

Alkyon Hydraulic Consultancy \& Research, 2003. Development and application of a large-scale morphological model of the Dutch coast: phase2: formulation and application of the PonTos-model version 1.4, prepared for: National Institute for Coastal and Marine Management/RijkwaterstaatRIKZ, by H.J. Steetzel and Z.B. Wang.

Bakker, W.T., 1969. The dynamics of a coast with a groyne system. Proceedings of 11th Coastal Engineering Conference, ASCE, 492-517.

Brøker, I., J. Zyserman, E.Ø. Madsen, K. Mangor and J. Jensen. 2007. Morphological Modelling: A Tool for Optimisation of Coastal Structures. Journal of Coastal Research, Vol. 23, Issue 5, 1148-1158.

Callaghan, D.P., F. Saint-Cast, P. Nielsen and T.E. Baldock, 2006. Numerical solutions of the sediment conservation law; a review and improved formulation for coastal morphological modelling, Coastal Engineering, Vol. 53, 557-571.

Dean, R.G. and Chui-Hee Yoo, 1992. Beach-Nourishment Performance Predictions, Journal of Waterway, Port, Coastal and Ocean Engineering, Vol. 118, ASCE, 567-585.

Deigaard, R., J. Fredsøe and I.B. Hedegaard, 1986. Mathematical Model for Littoral Drift, Journal of Waterway, Port, Coastal and Ocean Engineering, Vol. 112, ASCE, 351-369.

Drønen, N. and R. Deigaard, 2007. Quasi-three-dimensional modelling of the morphology of longshore bars, Coastal Engineering, Vol. 54, Elsevier, 197-215.

Fredsøe, J. and R. Deigaard, 1992. Mechanics of Coastal Sediment Transport, Advanced Series on Ocean Engineering, Vol. 3, World Scientific.

Grunnet, N., I. Brøker, E. Clausen and P. Sørensen, 2009. Improving bypass and increasing navigation depth: A vision for Hvide Sande harbour, Denmark. Proceedings of 6th International Conference on Coastal Dynamics, U286-U287.

Hansen, H.F., R. Deigaard, N. Drønen, 2005. A numerical hybrid model for the morphology of a barred coast with a river mouth, Proceedings of 29th International Conference on Coastal Engineering, ASCE, 2607-2619.

Hanson, H., 1989. Genesis - A Generalized Shoreline Change Numerical Model, Journal of Coastal Research, Vol. 5, Issue 1, 1-27.

Johnson, H.K. and J.A. Zyserman, 2002. Controlling spatial oscillations in bed level update schemes, Coastal Engineering, Vol. 46, Elsevier, 109-126.

Pelnard-Considère, R., 1956. Essai de Theorie de l'Evolution des Forms de Rivage en Plage de Sable et de Galets. Soc. Hydrotechnique de France, Quatriémes Journees de l'Hydraulique, Les Energies de la mer, Question III, Tome 1, 289-298.

Plant, N., R. Holman, M. Freilich and W. Birkemeier, 1999. A simple model for interannual sandbar behaviour, Journal of Geophysical Research, Vol. 104, American Geophysical Union, 15755-15776.

Roelvink, D., A. Reniers, van Dongeren, A. and D.J. Walstra, 2006. Modeling of Hurricane Impacts, Interim report 2.

Soulsby, R., 1997. Dynamics of marine sands. Thomas Telford Publications, ISBN: 072772584X. 